Article

\title{
Quantifying Roughness Coefficient Uncertainty in Urban Flooding Simulations through a Simplified Methodology
}

\author{
Vasilis Bellos ${ }^{1,2, *}(\mathbb{D})$, Ioannis M. Kourtis ${ }^{2}$, Antonio Moreno-Rodenas ${ }^{3}$ and \\ Vassilios A. Tsihrintzis ${ }^{4}$ \\ CH2M, Burderop Park, Swindon SN4 0QD, UK \\ 2 Laboratory of Reclamation Works and Water Resources Management, School of Rural and Surveying \\ Engineering, National Technical University of Athens, 9, Iroon Polytechniou str, Zografou, \\ Athens 15780, Greece; gkourtis@mail.ntua.gr \\ 3 Water Management Department, Civil Engineering and Geosciences, Technishe Universiteit Delft, 1, \\ Stevinweg, Delft 2628 CN, The Netherlands; a.m.morenorodenas@tudelft.nl \\ 4 Centre for the Assessment of Natural Hazards and Proactive Planning \& Laboratory of Reclamation Works \\ and Water Resources Management, School of Rural and Surveying Engineering, National Technical \\ University of Athens, 9, Iroon Polytechniou str, Zografou, Athens 15780, Greece; tsihrin@survey.ntua.gr or \\ tsihrin@otenet.gr \\ * Correspondence: vasilis.bellos@ch2m.com or vmpellos@mail.ntua.gr; Tel.: +30-210-772-2649
}

Received: 10 October 2017; Accepted: 30 November 2017; Published: 4 December 2017

\begin{abstract}
A methodology is presented which can be used in the evaluation of parametric uncertainty in urban flooding simulation. Due to the fact that such simulations are time consuming, the following methodology is proposed: (a) simplification of the description of the physical process; (b) derivation of a training data set; (c) development of a data-driven surrogate model; (d) use of a forward uncertainty propagation scheme. The simplification comprises the following steps: (a) unit hydrograph derivation using a 2D hydrodynamic model; (b) calculation of the losses in order to determine the effective rainfall depth; (c) flood event simulation using the principle of the proportionality and superposition. The above methodology was implemented in an urban catchment located in the city of Athens, Greece. The model used for the first step of the simplification was FLOW-R2D, whereas the well-known SWMM software (US Environmental Protection Agency, Washington, DC, USA) was used for the second step of the simplification. For the training data set derivation, an ensemble of 100 Unit Hydrographs was derived with the FLOW-R2D model. The parameters which were modified in order to produce this ensemble were the Manning coefficients in the two friction zones (residential and urban open space areas). The surrogate model used to replicate the unit hydrograph derivation, using the Manning coefficients as an input, was based on the Polynomial Chaos Expansion technique. It was found that, although the uncertainties in the derived results have to be taken into account, the proposed methodology can be a fast and efficient way to cope with dynamic flood simulation in an urban catchment.
\end{abstract}

Keywords: urban flooding; SWMM; FLOW-R2D; uncertainty; surrogate models; Polynomial Chaos Expansion

\section{Introduction}

Urban hydrology can be distinguished from rural hydrology, due to the fact that urban hydrology incorporates phenomena in different environments and that the dynamics of the flows are in different time scales. Therefore, there are still open challenges in modelling in this field, due to the great complexity of the urban environments, the number of processes involved in the urban water cycle, 
as well as the great influence that the dynamics and spatial variability of rainfall events have on a model's results. Urban flood modelling, as part of urban hydrology, is of great importance [1], because of the high risk it imposes on people and properties [2,3] as well as its increasing frequency of occurrence over the last decades. Due to the complexity of the urban environment, an accurate modelling of flooding demands at least a two-dimensional (2D) approach [4].

One of the scientific challenges in urban flooding is to cope with the parametric uncertainty [5-8]. There are several input parameters in urban hydrological models which create uncertainty. In this work, we only focussed on roughness coefficient uncertainty, since this parameter is characterised by a global nature and is used by nearly all models. The grid resolution is also of great importance and creates significant uncertainties. However, it was beyond the scope of this paper to study the uncertainty of the grid resolution, because it is common for a flood modeller to use it as an input information provided by external sources.

However, detailed, physically-based 2D hydrodynamic models are usually computationally expensive, i.e., the simulation time is in the magnitude of hours or days. Furthermore, a Monte Carlo-based, forward uncertainty propagation scheme needs thousands of simulations, and these two reasons make dealing with parametric uncertainty non-feasible. In order to tackle this problem, we propose the following four-step strategy: (a) developing a simplified approach to the physical process; (b) deriving a training data set for a surrogate model based on this simplification; (c) developing a data-driven surrogate model; (d) implementing the forward uncertainty propagation.

The first step of the proposed strategy is based on our previous work [9], in which a physically-based hydrodynamic model was used, in addition to the hydrological unit hydrograph (UH) theory, in an attempt to simulate the runoff of a real flash flood event in a rural catchment. The methodology for simplification consists of the following three steps: (a) the UH of the catchment is derived using a 2D hydrodynamic model; (b) the effective rainfall depth is calculated through determination of the losses using either empirical equations or software for hydrological analysis; (c) the final flood hydrograph is derived using the principle of proportionality and superposition.

The parameter which is under investigation for uncertainty is the Manning coefficients of the catchment, which is quite an important parameter in the simulation [10-12]. For the derivation of the training data set, one hundred (100) UHs were derived, adopting the Latin Hypercube Sampling technique for the values of the Manning coefficients. Using this training data set, we educated a computationally inexpensive surrogate model, based on the Polynomial Chaos Expansion technique, in order to produce the UHs. Finally, using this inexpensive surrogate model, we generated a Monte Carlo data set of ten thousand $(10,000)$ UHs assuming a uniform distribution for the Manning coefficients.

\section{Materials and Methods}

A short description of the methods and materials required for this study is presented, including

- the 2D hydrodynamic model used in the UH derivation, which is the in-house FLOW-R2D model [13];

- the SWMM software $[14,15]$ used in the calculation of the losses in order to derive the effective rainfall depth;

- the surrogate model, which is an in-house model based on a non-intrusive Polynomial Chaos Expansion technique [16];

- the area where the proposed strategy is implemented, which is a small urban catchment located in Kypseli, the centre of Athens, Greece.

\subsection{FLOW-R2D Model}

The FLOW-R2D model is a numerical solver based on the two-dimensional Shallow Water Equations (2D-SWE), using the Finite Difference Method (FDM) through a modification of the 
McCormack numerical scheme in a cell-centred, non-staggered computational grid. The model has been applied in urban environments [4] as well as in several case studies [17,18].

The 2D-SWE are written in the conservative form:

$$
\frac{\partial W}{\partial t}+\frac{\partial F}{\partial x}+\frac{\partial G}{\partial y}=D
$$

where

$$
W=\left|\begin{array}{c}
h \\
u h \\
v h
\end{array}\right|, F=\left|\begin{array}{c}
u h \\
u^{2} h+0.5 g h^{2} \\
u v h
\end{array}\right|, G=\left|\begin{array}{c}
v h \\
u v h \\
v^{2} h+0.5 g h^{2}
\end{array}\right|, D=\left|\begin{array}{c}
r-f \\
g h S_{0, x}-\tau_{b, x} / \rho \\
g h S_{0, y}-\tau_{b, y} / \rho
\end{array}\right|
$$

and $h$ is the water depth, $u$ is the horizontal component of flow velocity in the $x$-direction, $v$ is the horizontal component of flow velocity in the $y$-direction, $S_{0, x}$ and $S_{0, y}$ are the bottom slopes for the $x$ - and $y$-directions, respectively, and $\rho$ is the fluid density. The two source/sink terms in the Continuity Equation, $r$ and $f$, represent the precipitation rate and the rate of losses, such as infiltration or drainage (sink term), respectively. Shear stresses $\tau_{b, x}$ and $\tau_{b, y}$ can be modelled by various methods such as the Manning equation which is used in the present study, as follows:

$$
\frac{\tau_{b, x}}{\rho}=\frac{g n^{2} u\left(\sqrt{u^{2}+v^{2}}\right)}{R^{\frac{1}{3}}}, \frac{\tau_{b, y}}{\rho}=\frac{g n^{2} v\left(\sqrt{u^{2}+v^{2}}\right)}{R^{\frac{1}{3}}}
$$

where $n$ is the Manning coefficient and $R$ is the hydraulic radius.

For the numerical solution, a modified version of the explicit McCormack numerical scheme [19] is used. Including a diffusion factor in the discretisation of the 2D-SWE, artificial viscosity is added. In this way, we smoothen the oscillatory errors and, in parallel, retain the shock capturing capability of the scheme (the solution still has second-order accuracy). Wet/dry modelling is achieved through a water depth threshold which distinguishes the wet and the dry cells. In the dry cells, the water depth and the flow velocity are taken as zeros. In the following equations, the discretisation of the 2D-SWE using the McCormack numerical scheme is obtained in two steps, i.e., a predictor strep in Equation (4) and a corrector step in Equation (5):

$$
\begin{gathered}
W_{i, j}^{*}=W_{i, j}^{k}-\frac{\Delta t}{\Delta x}\left(F_{i+1, j}^{k}-F_{i, j}^{k}\right)-\frac{\Delta t}{\Delta y}\left(G_{i, j+1}^{k}-G_{i, j}^{k}\right)+\Delta t D_{i, j}^{k} \\
\begin{aligned}
W_{i, j}^{k+1}=\frac{1}{2}\left[\omega W_{i, j}^{k}+\frac{1}{4}(1-\omega)\left(W_{i+1, j}^{k}+W_{i-1, j}^{k}+W_{i, j+1}^{k}+W_{i, j-1}^{k}\right)+W_{i, j}^{*}\right. \\
\left.-\frac{\Delta t}{\Delta x}\left(F_{i, j}^{*}-F_{i-1, j}^{*}\right)-\frac{\Delta t}{\Delta y}\left(G_{i, j}^{*}-G_{i, j-1}^{*}\right)+\Delta t D_{i, j}^{*}\right]
\end{aligned}
\end{gathered}
$$

where $\Delta t, \Delta x$ and $\Delta y$ are the time step, and the space steps in the $x$-and $y$-directions, respectively, and $\omega$ is the diffusion factor.

\subsection{SWMM Software}

EPASWMM5 is a fully dynamic rainfall-runoff simulation model which combines a hydrological model in urban scale with an urban drainage hydraulic model, the latter of which simulates water flow in the sewer system [14,15]. The software can be used in the design, analysis, and planning of drainage systems as well as simulating the runoff quantity and quality [20-28]. In addition, several attempts have been made to calibrate the parameters required by the software [29,30] and using it in order to compare against machine learning techniques [31].

For the conversion of excess precipitation into the overland flow for each subcatchment of the system, SWMM uses a nonlinear reservoir model. Inflow in each subcatchment comes from precipitation, while losses are due to infiltration, evaporation, and depression storage (initial rainfall abstractions). 
The urban drainage hydraulic model in SWMM is based on mass, momentum, and energy conservation laws. Flow routing along the conduits of the drainage network can be simulated with three different methods [15]: (a) the Steady Flow (SF) method; (b) the Kinematic Wave (KW) method; (c) the Dynamic Wave (DW) method. The SF method assumes that flow is uniform and steady on each computational time step; the KW method solves the one-dimensional Shallow Water Equations (1D-SWE) ignoring both inertial and pressure forces; finally, the DW method solves the full form of the 1D-SWE.

The SWMM software is used here to calculate the rainfall losses and then determine the effective rainfall depth. It should be noted that, although the losses in the rural setting are mainly dominated by infiltration, for urban settings, losses are mainly due to the runoff diverted in the sewers of the system, the initial rainfall abstraction (interception, ponding, and wet surface), and, to a lesser extent, the infiltration phenomenon.

\subsection{Surrogate Model}

Parametric uncertainty propagation schemes of environmental models are often performed through Monte Carlo sampling techniques [32]. This is based on drawing pseudo-random samples from the random variables probabilistic space and then evaluating the simulator. Those simulations can be performed in parallel, thus accelerating the convergence process. However, obtaining sufficient samples to guarantee convergence can become impractical when the simulator is computationally expensive. In those cases, it is possible to propose a functional representation of the model, which approximates its behaviour with respect to the parameter values. This is often referred to as surrogate or meta-modelling [33-35]. A polynomial orthogonal expansion is a method to create surrogate structure for space-time-dependent models [16].

Since one of the goals of this work is to replicate a physically-based detailed model (simulator) which derives a UH, we can define the model as:

$$
Q(t)=M\left[I(t), x_{0}, \theta\right]
$$

where $M$ represents a set of differential equations governing the process, $I(t)$ is the model dynamic inputs, $x_{0}$ is the initial system conditions, and $\theta$ is a set of uncertain model parameters.

The objective of a polynomial expansion is to define an approximate mapping of the parameter values to the real simulator's response. This requires the assumption that the response of $M$ is smooth with respect to the parameter values. The approximation takes form as a weighted combination of polynomials:

$$
M\left[I(t), x_{0}, \theta\right] \approx \hat{M}=\sum_{i=1,2 \cdots n} c_{i}\left(I(t), x_{0}\right) \cdot \varphi_{i}(\theta)
$$

in which $\varphi_{i}(\theta)$ is a series of orthogonal polynomials constructed as the basis of the joint probability density function of the uncertain parameters, and $c_{i}\left(I(t), x_{0}\right)$ is a set of coefficients to be fitted to the particular model response.

The orthogonal polynomial series for the Normal and Uniform parametric probability distributions can be found in the Wiener-Askey scheme [36] (defined by Hermite and Legendre polynomials, respectively), whereas distributions not included at the Wiener-Askey scheme can still be used through generalized polynomial chaos schemes [33]. The expansion coefficients can be computed through a point-collocation scheme. This involves sampling the simulator $k$ times and extracting the coefficients by the least squares fitting from the known parameter-output couples. Once fitted, the meta-model or surrogate can be evaluated several orders of magnitude faster than the original simulator, allowing us to perform an approximated parametric uncertainty quantification.

It should be noted that a more comprehensive description of Polynomial Chaos Expansion theory is beyond the scope of this paper. Hence, for more details, the reader could see the relevant literature, e.g., $[16,33,37]$. 


\subsection{Area of Application of the Methodology}

The area of application and validation of the proposed methodology consists of a small urban catchment located in the centre of Athens (Greece), in a neighbourhood called Kypseli. The area is highly populated and characterised by dense urban development (multi-story buildings and generally limited open space). However, in the specific drainage area, there exist some open spaces due to the existence of hills at the upper part of the drainage area. The percent impervious of the study area is estimated at about $46 \%$. Figure 1 presents a satellite view of the urban catchment and the location of the urban open space. It should be mentioned that this is one of the few areas in Athens, and Greece in general, where a combined sewer system is still in operation.
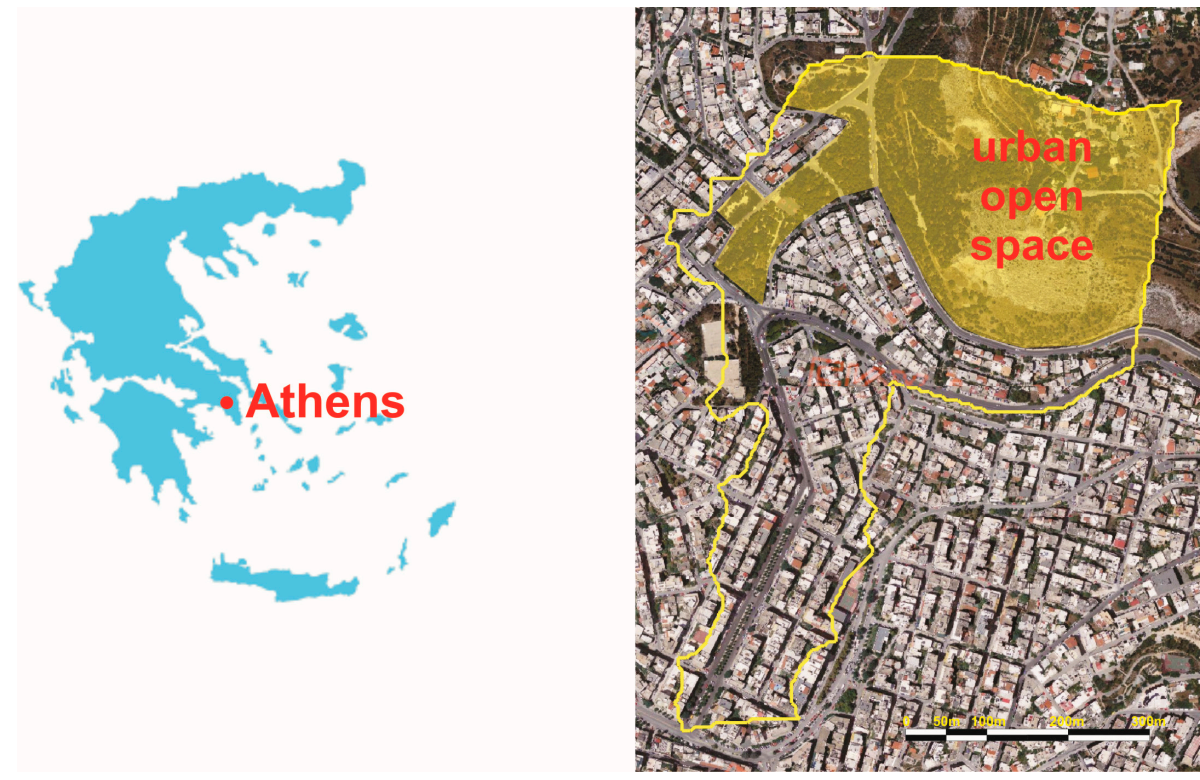

Figure 1. Boundaries of the catchment and location of the open urban space (National Cadastre \& Mapping Agency of Greece, Cholargos, Greece, www.ktimatologio.gr).

Based on the combined drainage network characteristics, the hydrologic and hydraulic conditions, and, of course, the main principles of SWMM software, the area was delineated into 7 subcatchments. The total drainage area of the study site is approximately 28.08 ha with the area of the subcatchments ranging from 0.74 ha to 8.98 ha. The slopes in the study area range from $7 \%$ to $22 \%$, with an average slope of $13 \%$. The combined drainage network consists of 26 nodes and 25 combined sewer lines, with a total length of about $1.1 \mathrm{~km}$. The sewer network comprises either egg-shaped sewers, with characteristic vertical dimensions ranging from $0.9 \mathrm{~m}$ to $1.2 \mathrm{~m}$, or circular sewers, with diameters of $0.4 \mathrm{~m}$. The slopes of the sewers range from 0.4 to $25.0 \%$.

Subcatchment information, such as area, slope, and the average maximum length were extracted using ArcGIS, from the Digital Terrain Model (DTM), with a $5 \times 5 \mathrm{~m}$ grid size. The width of each subcatchment was calculated as the area divided by the average maximum length of each subcatchment [14].

\section{Results}

\subsection{Simplification}

In this section, we describe, in detail, the process followed in order to simplify the urban flooding simulation using the FLOW-R2D model and the SWMM software. Thereafter, we present the results derived from the principle of superposition, as previously described. 


\subsubsection{UH Derivation Using FLOW-R2D}

Due to the fact that the computational domain is a built-up area, the dominant element of the simulation is the way in which the buildings are represented. There are several ways for representing the buildings in the relative literature $[4,38]$. In order to represent the complexity of the city's infrastructure, due to the fact that the Digital Terrain Model (DTM) is relatively coarse, the computational domain was categorised into two friction zones: (a) the residential area; and (b) the urban open space.

Regarding the input data, the DTM consisted of a grid with a resolution of $5 \times 5 \mathrm{~m}$, as previously mentioned. Ten-minute UHs were derived, hence the input rainfall had an intensity of $1.67 \mathrm{~mm} / \mathrm{h}$. Regarding the required parameters, based on past experience [9], the time step was determined as $\Delta t=10^{-3} \mathrm{~s}$, the threshold which distinguishes the wet and dry cells as $h_{d r y}=10^{-4} \mathrm{~m}$, and the diffusion factor as $\omega=0.99$.

For mass conservation purposes, each of the derived UHs is multiplied by a correction factor, which was determined by dividing the volume of the water entered in the computational domain through rainfall by the volume of the water of the UH [9]. The time step of the UH was $30 \mathrm{~s}$.

\subsubsection{Effective Rainfall Determination Using SWMM}

The calculation of losses was performed using the SWMM software. It was clarified that, in our case, we consider three sources of losses: (a) the runoff inflows to the sewer system; (b) the infiltration; (c) the initial abstraction due to interception, ponding, and wet surface.

The various required parameters of the model were calibrated against observed data recorded in the urban drainage system. The observed data were obtained from a storm event which occurred on the 24 February 2006 [39]. The following parameters were used in a manual calibration: (a) the width of the subcatchments; (b) the percentage of the impervious area in each subcatchment of the system; (c) the Manning coefficients of the pervious and the impervious area; (d) the initial abstraction depths of the pervious and impervious areas; (e) the Manning coefficient on the sewer system. Table 1 presents the calibrated values of these parameters for all subcatchments, in which the drainage area was divided. Figure 2 presents the comparison between the simulation results derived by the SWMM and the measured data. A good comparison is shown in terms of the magnitude of the peak, and general shape of the predicted hydrograph. It is noted that, as far as the urban drainage model is concerned, the dynamic wave method was used.

Due to the fact that no flooding was observed on the surface of the catchment during this event, a 6-h duration synthetic storm was generated in order to test the proposed methodology. The hypothetical storm comprised two parts: a first part in which the rainfall intensity was low, called Event 1, and a second part in which the rainfall intensity was too high, called Event 2 (Figure 3). Figure 4 presents the losses due to the runoff diverted into the sewers of the system, the infiltration and the initial abstraction, assuming that the various required input parameters of SWMM take the values derived in the calibration phase (Table 1).

Table 1. Calibrated parameters for the SWMM software.

\begin{tabular}{|c|c|c|c|c|c|c|c|}
\hline \multirow{3}{*}{ Parameter } & \multicolumn{7}{|c|}{ Calibration } \\
\hline & \multicolumn{7}{|c|}{ Subcatchment } \\
\hline & 1 & 2 & 3 & 4 & 5 & 6 & 7 \\
\hline Width (m) & 82.1 & 136.9 & 341.9 & 133.2 & 998.2 & 835.5 & 592.1 \\
\hline Impervious area (\%) & 23.2 & 55.3 & 64.8 & 46.0 & 43.1 & 12.0 & 76.9 \\
\hline Manning coefficient of the impervious area $\left(\mathrm{s} / \mathrm{m}^{1 / 3}\right)$ & 0.015 & 0.015 & 0.015 & 0.015 & 0.015 & 0.015 & 0.015 \\
\hline Manning coefficient of the pervious area $\left(\mathrm{s} / \mathrm{m}^{1 / 3}\right)$ & 0.2 & 0.2 & 0.2 & 0.2 & 0.2 & 0.2 & 0.2 \\
\hline Initial abstraction of the impervious area $(\mathrm{mm})$ & 2.54 & 2.54 & 2.54 & 2.54 & 2.54 & 2.54 & 2.54 \\
\hline Initial abstraction of the pervious area (mm) & 6.51 & 6.51 & 6.51 & 6.51 & 6.51 & 6.51 & 6.51 \\
\hline Manning coefficient of the sewer system $\left(\mathrm{s} / \mathrm{m}^{1 / 3}\right)$ & 0.013 & 0.013 & 0.013 & 0.013 & 0.013 & 0.013 & 0.013 \\
\hline
\end{tabular}




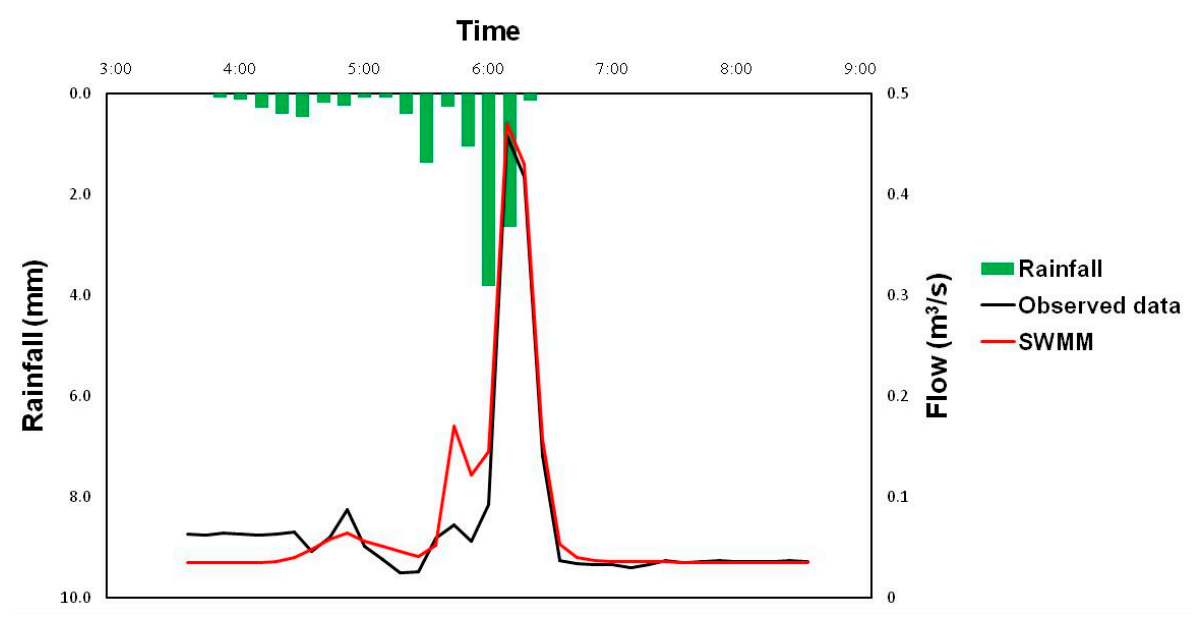

Figure 2. Comparison of hydrographs observed and predicted by SWMM during the calibration phase.

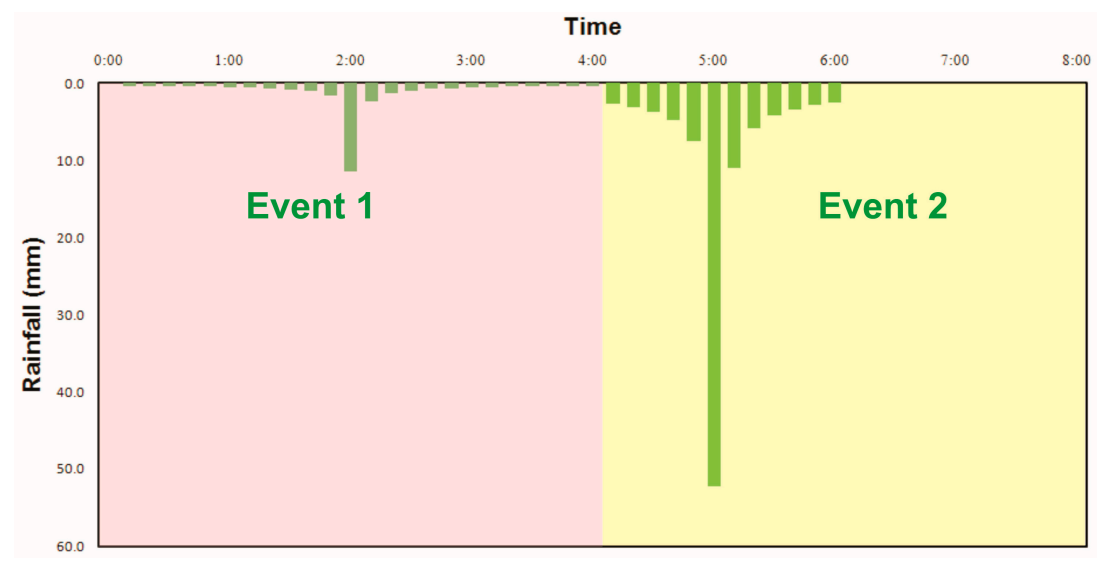

Figure 3. Hypothetical storm with two subsequent events of low and high intensity.

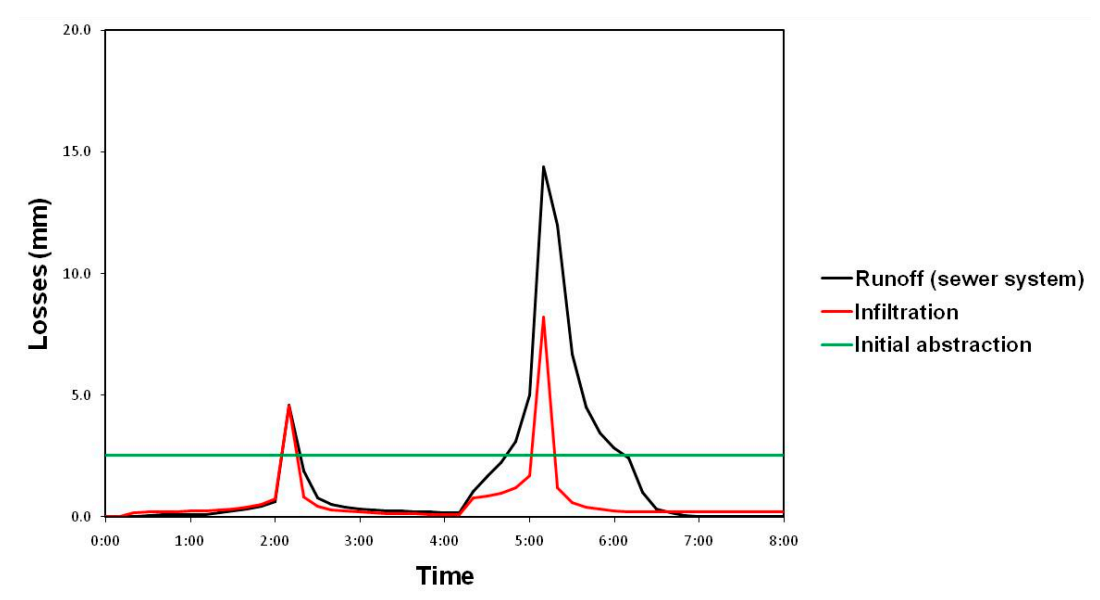

Figure 4. Predicted losses by SWMM software.

\subsubsection{Flooding Simulation}

For the final step of the simplification process, the flood event was simulated using the principle of proportionality and superposition. First, based on the principle of proportionality, the effective rainfall depth (which had a time step of $10 \mathrm{~min}$ ) was multiplied by the components of the UH (which have a time step of $30 \mathrm{~s}$ ). Then, each multiplied UH was shifted twenty time steps, in order to preserve the 
fact that every multiplied UH referred to the corresponding effective rainfall depth time step. Finally, based on the principle of superposition, the flood event was simulated, summing the multiplied and shifted UHs for each time step.

\subsection{Training Data Set}

In order to create a training data set for the surrogate model, $100 \mathrm{UHs}$ were derived using different combinations of Manning coefficients for the two friction zones. The sampling was made using the Latin Hypercube Sampling technique, assuming that the Manning coefficient in the main urban area ranges from 0.02 to $0.05 \mathrm{~s} / \mathrm{m}^{1 / 3}$, whereas it ranges from 0.03 to $0.08 \mathrm{~s} / \mathrm{m}^{1 / 3}$ in the urban open space area. Figure 5 shows the interval which encloses all the UHs derived in the training process.

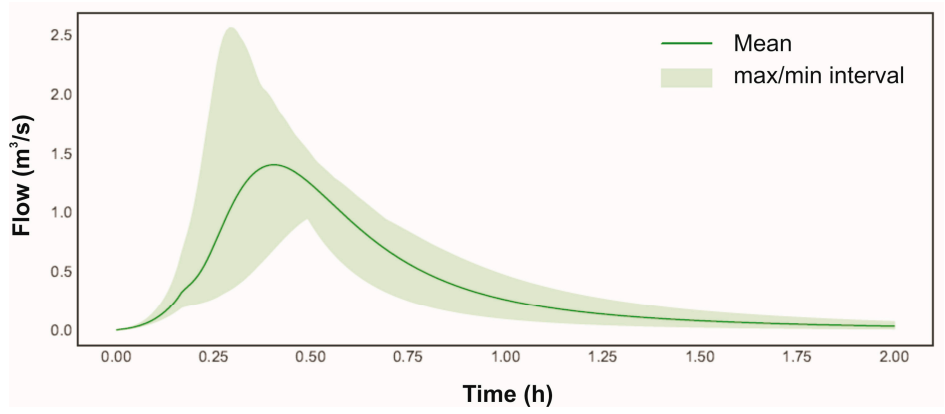

Figure 5. Interval which encloses the derived $100 \mathrm{UHs}$ (training data set).

It should be mentioned that the derivation of each UH required about one day of the computational budget. The derivation of 100 UHs would be very difficult unless a High Performance Computing (HPC) platform was used. In this work, the HPC platform of the Computational Centre of the National Technical University of Athens was used, which consists of a cluster with 24 cores.

\subsection{Implementation of Surrogate Model}

As mentioned previously, two parameters were considered as a source of uncertainty: (a) the Manning coefficient in the main urban area $\left(n_{u}\right)$; (b) the Manning coefficient in the urban open space area $\left(n_{r}\right)$. The parameters were sampled from uniform and independent joint probability. Legendre polynomials were used to generate an orthogonal basis. The bivariate polynomial expansion was obtained by multiplying the univariate ones (valid as long as the parameter space is stochastically independent). The polynomial basis was truncated at fourth order. This combination of two-dimensional parametric space and four grade polynomial series led to a series of 15 orthogonal polynomials, which was used in the approximation process.

In total, $80 \%$ of the training data set of 100 UHs was used for the fitting phase, whereas the remaining $20 \%$ was used for the validation phase (testing data set). The 15 coefficient sets $c_{i}\left(I\left(t, x_{0}\right)\right.$ (each one associated to each polynomial) were fitted through the least squares method from the known 80 nodes (known parameter-output couples). Once the coefficient values were obtained, a new sample of the surrogate model was obtained by evaluating the polynomial series at the new parametric value and multiplying by the coefficient vector (Equation (7)).

For the performance of the surrogate model, the Nash-Sutcliffe (NSE) efficiency coefficient [40] was used between the UHs derived by the FLOW-R2D and the UHs derived by the surrogate model in the testing data set (Figure 6). The calculated NSE values (close to unit) indicate the high performance of the developed surrogate model for the emulation of FLOW-R2D response. 


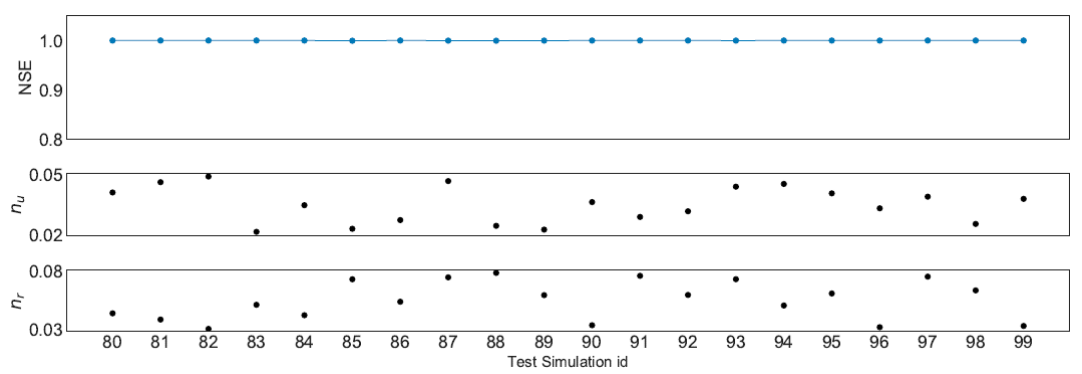

Figure 6. Performance of the surrogate model for the testing data set.

\subsection{Forward Uncertainty Propagation}

Finally, we performed a forward parametric uncertainty propagation of the two Manning coefficients. We generated a Monte Carlo data set of 10,000 flood simulations using the computationally inexpensive surrogate model, assuming a uniform distribution for the values of the two investigated parameters. The range of the uniform distribution is the same range used for the training data set generation (urban areas from 0.02 to $0.05 \mathrm{~s} / \mathrm{m}^{1 / 3}$ and urban open space areas from 0.03 to $0.08 \mathrm{~s} / \mathrm{m}^{1 / 3}$ ).

Figure 7 presents the mean and the band of $75 \%$ and $95 \%$ confidence of the solution. For the two flood peaks (Event 1 and Event 2), we tried to fit a lognormal distribution with statistical characteristics, a mean $(\mu)$ and a standard deviation $(\sigma)$, in order to quantify the uncertainty. The statistical characteristics for Event 1 were $\mu=0.164$ and $\sigma=0.261$, and those for Event 2 were $\mu=1.935$ and $\sigma=0.275$. Figure 8 presents the fitting of the lognormal Probability Density Function (PDF) to the observed data for both Events. The objective function used in the fitting was the well-known Pearson correlation coefficient between fitted and observed data, which was 0.97 for Event 1 and 0.95 for Event 2, correspondingly.

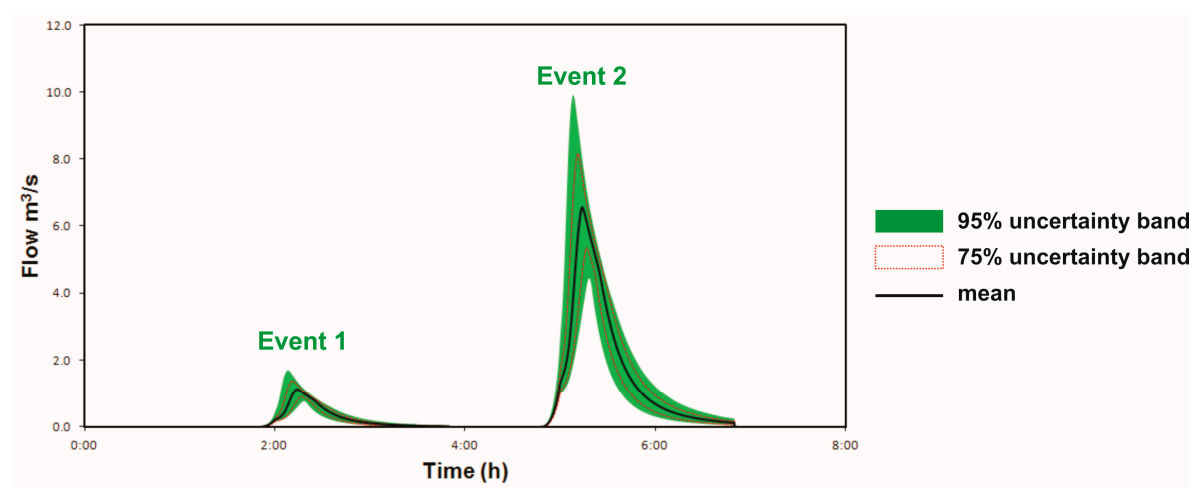

Figure 7. Uncertainty bands and mean of the urban flood hydrograph using the proposed methodology.

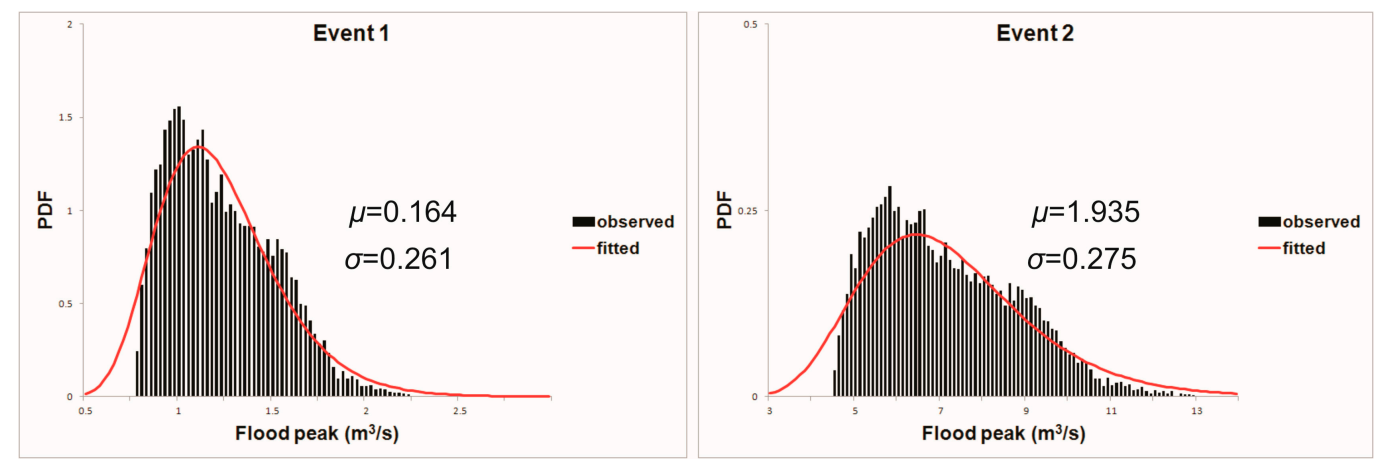

Figure 8. Probability Density Function (PDF) for observed and fitted flood peaks for Event 1 and Event 2. 


\section{Discussion}

It can be noticed from Figures 7 and 8 that, as far as the peak of the flood events is concerned, significant uncertainties exist and, hence, the range of the Manning coefficients is of high importance. Specifically, for Event 1, the flood peak for the $95 \%$ uncertainty band ranges from $0.8 \mathrm{~m}^{3} / \mathrm{s}$ to $1.7 \mathrm{~m}^{3} / \mathrm{s}$, whereas for Event 2, the corresponding interval ranges from $5.0 \mathrm{~m}^{3} / \mathrm{s}$ to $10.0 \mathrm{~m}^{3} / \mathrm{s}$. On the other hand, the corresponding time moment of the flood peak seems to be less sensitive to the roughness coefficient. It seems that the uncertainty band is greater for Event 2 than for Event 1 . However, if we normalize dividing the $95 \%$ and the $50 \%$ intervals with the mean for both events, the results become equal ( 0.76 and 0.37 for the $95 \%$ and $50 \%$ intervals, respectively). From Figure 8 , it can be noticed that there is a skewness in the lower values of the distribution.

One disadvantage of the methodology is that, with the given computational power, the methodology can be implemented in relatively small catchments. However, the proposed methodology can be a useful, fast tool in the decision-making process, flood warning schemes, etc., in comparison to the time-consuming, physically-based 2D models, since it can cope with the dynamics of the flooding occurring on the catchment surface, in comparison to the typical 1D/1D urban drainage models, which consist of 1D simulation both in surface and drainage flow [26]. There is still a need for further testing of the methodology with observed data, although, generally, there is lack of data in urban flooding case studies.

Although there are several proposed values for the Manning coefficients in the literature, it is found that, in the majority of real world applications, the values of these coefficients are significantly higher than those of the literature [11,41] due to the fact that they compensate for the various energy losses occurring in real world flood events. Therefore, a careful strategy should be adopted in the selection of these values, coupling the modeller's experience and existing data, in order to either perform a calibration phase or narrow the range of values. The quantification of the parametric uncertainty is quite useful information in order to cope with this challenge.

\section{Conclusions}

In this paper, a methodology for quantifying the parametric uncertainty due to friction in urban flooding simulations is presented. Due to the fact that urban flooding modelling is often computationally expensive, we propose that the quantification of uncertainty should follow these four steps: (a) simplification of the physical process; (b) derivation of a training data set; (c) development of a data-driven surrogate model; (d) forward uncertainty propagation.

For simplification, we used a methodology already implemented in rural catchments, which consists of the following steps: (a) the unit hydrograph of the urban catchment is derived using a 2D hydrodynamic model; (b) the losses are calculated in order to determine the effective rainfall depth; (c) the flood event is simulated using the principle of proportionality and superposition. For the unit hydrograph derivation, the FLOW-R2D model was used, whereas the calculation of the losses was made with the SWMM software.

The application of the above methodology was made in a small urban catchment, located in the centre of Athens, Greece, for which flow measurements were available for SWMM calibration. Uncertainty in the derived results due to the Manning coefficients was quantified and found to be significant. Despite this fact, and adopting a more careful strategy in friction modelling, the method can simulate the dynamics of the flood on the catchment surface in a fast and efficient way and can, therefore, be a useful tool in decision-making processes.

Acknowledgments: This research was done as part of the Marie Curie ITN-Quantifying Uncertainty in Integrated Catchment Studies (QUICS) project. This project has received funding from the European Union's Seventh Framework Programme for research, technological development, and demonstration under grant agreement No. 60700. The Computer Centre of NTUA is acknowledged for the access provided to the use of the computer facilities. 
Author Contributions: V.B. developed the framework and the methodology, implemented the FLOW-R2D simulations, and wrote this paper. I.M.K. implemented the SWMM simulations and contributed to the writing. A.M.-R. developed the framework, the surrogate model, and contributed to the writing. V.A.T. contributed to the writing and supervised the work.

Conflicts of Interest: The authors declare no conflict of interest.

\section{References}

1. Jha, K.A.; Bloch, R.; Lamond, J. Cities and Flooding: A Guide to Integrated Urban Flood Risk Management for the 21st Century; The World Bank Publications: Washington, DC, USA, 2012.

2. Tsakiris, G. Flood risk assessment: Concepts, modelling, applications. Nat. Hazards Earth Syst. Sci. 2013, 2, 261-286. [CrossRef]

3. Pistrika, A.; Tsakiris, G.; Nalbantis, I. Flood depth-damage functions for built environment. Environ. Process. 2014, 1, 553-572. [CrossRef]

4. Bellos, V.; Tsakiris, G. Comparing various methods of building representation for 2D flood modelling in built-up areas. Water Resour. Manag. 2015, 29, 379-397. [CrossRef]

5. Tsubaki, R.; Kawahara, Y. The uncertainty of local flow parameters during inundation flow over complex topographies with elevation errors. J. Hydrol. 2013, 486, 71-87. [CrossRef]

6. Jung, Y.; Merwade, V. Estimation of uncertainty propagation in flood inundation mapping using a 1-D hydraulic model. Hydrol. Process. 2015, 29, 624-640. [CrossRef]

7. Ioss, B.; Lemaitre, P. A review on global sensitivity analysis methods. In Uncertainty Management in Simulation-Optimization of Complex Systems; Springer: New York, NY, USA, 2015; pp. 101-122.

8. Abily, M.; Bertrand, N.; Delestre, O.; Gourbesville, P.; Duluc, C.M. Spatial global sensitivity analysis of high resolution classified topographic data use in 2D urban flood modelling. Environ. Model. Softw. 2016, 77, 183-195. [CrossRef]

9. Bellos, V.; Tsakiris, G. A hybrid method for flood simulation in small catchments combining hydrodynamic and hydrological techniques. J. Hydrol. 2016, 540, 331-339. [CrossRef]

10. Pappenberger, F.; Beven, K.; Horritt, M.; Blazkova, S. Uncertainty in the calibration of effective roughness parameters in HEC-RAS using inundation and downstream level observations. J. Hydrol. 2005, 302, 46-69. [CrossRef]

11. Christelis, V.; Bellos, V.; Tsakiris, G. Employing surrogate modelling for the calibration of a 2D flood simulation model. In Sustainable Hydraulics in the Era of Global Change, Proceedings of 4th IAHR Congress, Liege, Belgium, 27-29 July 2016; Erpicum, S., Dewals, B., Archambeau, P., Pirotton, M., Eds.; CRC Press: Boca Raton, FL, USA, 2016; pp. 727-732.

12. Papaioannou, G.; Vasiliades, L.; Loukas, A.; Aronica, G.T. Probabilistic flood inundation mapping at ungauged streams due to roughness coefficient uncertainty in hydraulic modelling. Adv. Geosci. 2017, 44, 23-34. [CrossRef]

13. Tsakiris, G.; Bellos, V. A numerical model for two-dimensional flood routing in complex terrains. Water Resour. Manag. 2014, 28, 1277-1291. [CrossRef]

14. Rossman, L.A.; Huber, W.C. Storm Water Management Model, Reference Manual Volume I-Hydrology (Revised); US Environmental Protection Agency: Washington, DC, USA, 2016.

15. Rossman, L.A. Storm Water Management Model, Reference Manual Volume II-Hydraulics; US Environmental Protection Agency: Washington, DC, USA, 2017.

16. Xiu, D. Numerical Methods for Stochastic Computations: A Spectral Method Approach; Princeton University Press: Princeton, NJ, USA, 2010.

17. Bellos, V.; Tsakiris, G. 2D Flood Modelling: The case of Tous dam break. In Proceedings of the 36th IAHR World Congress, The Hague, The Netherlands, 28 June-3 July 2015.

18. Papadaki, C.; Bellos, V.; Ntoanidis, L.; Dimitriou, E. Comparison of West Balkan adult trout habitat predictions using a pseudo-2D and a 2D hydrodynamic model. Hydrol. Res. 2016, 48, 1697-1709. [CrossRef]

19. McCormack, R.W. The effect of viscosity in hypervelocity impact cratering. In Proceedings of the AIAA Hypervelocity Impact Conference, Cincinnati, OH, USA, 30 April-2 May 1969; pp. 69-354.

20. Tsihrintzis, V.A.; Hamid, R. Runoff quality prediction from small urban catchments using SWMM. Hydrol. Process. 1998, 12, 311-329. [CrossRef] 
21. Hsu, M.H.; Chen, S.H.; Chang, T.J. Inundation simulation for urban drainage basin with storm sewer system. J. Hydrol. 2000, 234, 21-37. [CrossRef]

22. El-Sharif, A.; Hansen, D. Application of SWMM to the flooding problem in Truro, Nova Scotia. Can. Water Resour. J. 2001, 26, 439-459. [CrossRef]

23. Carbone, M.; Mancuso, A.; Piro, P. Porous pavement quality modelling. Procedia Eng. 2014, 89, 758-766. [CrossRef]

24. Palla, A.; Gnecco, I. Hydrologic modeling of low impact development systems at the urban catchment scale. J. Hydrol. 2015, 528, 361-368. [CrossRef]

25. Jiang, L.; Chen, Y.; Wang, H. Urban flood simulation based on the SWMM model. IAHS-AISH Proc. Rep. 2015, 368, 186-191.

26. Zhu, Z.; Chen, Z.; Chen, X.; He, P. Approach for evaluating inundation risks in urban drainage systems. Sci. Total Environ. 2016, 553, 1-12. [CrossRef] [PubMed]

27. Kourtis, I.M.; Bellos, V.; Tsihrintzis, V.A. Comparison of 1D-1D and 1D-2D urban flood models. In Proceedings of the 15th International Conference on Environmental Science and Technology (CEST 2017), Rhodes, Greece, 31 August-2 September 2017.

28. Kourtis, I.M.; Kopsiaftis, G.; Bellos, V.; Tsihrintzis, V.A. Calibration and sensitivity analysis of a small urban catchment in Athens Greece using SWWM model. In Proceedings of the 15th International Conference on Environmental Science and Technology (CEST 2017), Rhodes, Greece, 31 August-2 September 2017.

29. Liong, S.Y.; Chan, W.T.; ShreeRam, J. Peak-flow forecasting with genetic algorithm and SWMM. J. Hydraul. Eng. 1995, 121, 613-617. [CrossRef]

30. Barco, J.; Wong, K.M.; Stenstrom, M.K. Automatic calibration of the U.S. EPA SWMM model for a large urban catchment. J. Hydraul. Eng. 2008, 134, 466-474.

31. Granata, F.; Gargano, R.; Marinis, G. Support vector regression for rainfall-runoff modeling in urban drainage: A comparison with EPA's Storm Water Management Model. Water 2016, 8, 69. [CrossRef]

32. Fishman, G. Monte Carlo: Concepts, Algorithms and Applications; Springer: New York, NY, USA, 2013.

33. O'Hagan, A. Polynomial Chaos: A tutorial and critique from statistician's perspective. J. Uncertain. Quantif. 2013, 20, 1-20.

34. Asher, M.J.; Croke, B.F.W.; Jakeman, A.J.; Peeters, L.J.M. A review of surrogate models and their application to groundwater modelling. Water Resour. Res. 2015, 51, 5957-5973. [CrossRef]

35. Carbajal, J.P.; Leitao, J.P.; Albert, C.; Rieckermann, J. Appraisal of data-driven and mechanistic emulators of nonlinear simulators: The case of hydrodynamic urban drainage models. Environ. Model. Softw. 2017, 92, 17-27. [CrossRef]

36. Xiu, D.; Karniadakis, G.E. Modeling uncertainty in flow simulations via generalized polynomial chaos. J. Comput. Phys. 2003, 187, 137-167. [CrossRef]

37. Xiu, D.; Karniadakis, G.E. The Wiener-Askey polynomial chaos for stochastic differential equations. SIAM J. Sci. Comput. 2002, 24, 619-644. [CrossRef]

38. Bellos, V. Ways for flood hazard mapping in urbanised environments: A short literature review. Water Util. J. 2012, 4, 25-31.

39. Antonaropoulos, P. Associates. In Technical Report: Demonstration of a European Knowledge Management Framework for a Procedure on Waste-Water Asset Management (Contract Nr. IPS-2001-42115)_Application of the Hydroplan Methodology in the Pilot Area of Athens; EYDAP S.A.: Galatsi, Greece, 2006. (In Greek)

40. Nash, J.E.; Sutcliffe, J.V. River flow forecasting through conceptual models, Part I-A discussion of principles. J. Hydrol. 1970, 10, 282-290. [CrossRef]

41. Jarrett, R. Determination of Roughness Coefficients for Streams in Colorado; Water Resources Investigation Report 85-4004; US Geological Survey: Reston, VA, USA, 1985.

(C) 2017 by the authors. Licensee MDPI, Basel, Switzerland. This article is an open access article distributed under the terms and conditions of the Creative Commons Attribution (CC BY) license (http:// creativecommons.org/licenses/by/4.0/). 